University of Wollongong

Research Online

Faculty of Social Sciences - Papers (Archive) Faculty of Arts, Social Sciences \& Humanities

2018

Determinants of knowledge and attitudes about sugar and the association of knowledge and attitudes with sugar intake among adults: A systematic review

Adyya Gupta

University of Wollongong, ag654@uowmail.edu.au

Lisa Smithers

University of Adelaide

Jane Harford

University of Adelaide

Tracy Merlin

University of Adelaide

Annette J. Braunack-Mayer

University of Wollongong, abmayer@uow.edu.au

Follow this and additional works at: https://ro.uow.edu.au/sspapers

Part of the Education Commons, and the Social and Behavioral Sciences Commons

Research Online is the open access institutional repository for the University of Wollongong. For further information contact the UOW Library: research-pubs@uow.edu.au 


\title{
Determinants of knowledge and attitudes about sugar and the association of knowledge and attitudes with sugar intake among adults: A systematic review
}

\author{
Abstract \\ Efforts to reduce sugar intake levels have been primarily limited to increasing knowledge and changing \\ attitudes. We conducted a systematic review to (1) identify factors influencing adults' knowledge and \\ attitudes about sugar, and (2) determine if there is an association between knowledge and attitudes \\ about sugar and sugar intake. We searched 15 electronic databases from inception to December 2016 for \\ English language publications including adults with relevant exposure and outcome measures. Findings \\ were summarised meta-narratively. Of 3287 studies, 22 studies ( 14 for objective one and 8 for objective \\ two) were included. Individual (liking of sugary food), interpersonal (attitudes of peers) and environmental \\ factors (media, health professionals and food labelling) influenced adults' knowledge and attitudes about \\ sugar, at least to some extent. Overall, quality of the studies included in our review was weak, and \\ evidence for the application of the Knowledge-Attitude-Behavior model for understanding sugar intake is \\ limited. Protocol registered in the PROSPERO International prospective register of systematic reviews \\ (registration number CRD42015027540).

\section{Disciplines} \\ Education | Social and Behavioral Sciences

\section{Publication Details} \\ Gupta, A., Smithers, L. G., Harford, J., Merlin, T. \& Braunack-Mayer, A. (2018). Determinants of knowledge \\ and attitudes about sugar and the association of knowledge and attitudes with sugar intake among \\ adults: A systematic review. Appetite, 126 185-194.
}




\section{Title Page}

2 Title: Determinants of knowledge and attitudes about sugar and the association of knowledge

3 and attitudes with sugar intake among adults: A systematic review

4 Author names: Adyya Gupta ${ }^{1}$, Lisa G. Smithers ${ }^{1}$, Jane Harford ${ }^{2}$, Tracy Merlin ${ }^{3}$, Annette

5 Braunack-Mayer ${ }^{1 *}$

6 Authors affiliations:

$7 \quad{ }^{1}$ School of Public Health, University of Adelaide, Adelaide, South Australia, Australia

$8{ }^{2}$ Australian Research Centre for Population Oral Health (ARCPOH), School of Dentistry,

9 University of Adelaide, Adelaide, South Australia, Australia

$10{ }^{3}$ Adelaide Health Technology Assessment, School of Public Health, University of Adelaide,

11 Adelaide, South Australia, Australia

12

$13 *$ Corresponding author

14 Prof. Annette Braunack-Mayer

15 School of Public Health

16 Level 9, Adelaide Health and Medical Sciences Building

17 University of Adelaide, Australia SA 5005

18 Phone: +61883131694

19 Email:

annette.braunackmayer@adelaide.edu.au 
High sugar intake is a risk factor for several non-communicable diseases (Gibson, 2008; Imamura et al., 2015; Sheiham \& James, 2014; Te Morenga, Mallard, \& Mann, 2013). Sugar (including total, added and free sugars) intake above recommended levels is a global public health concern and the World Health Organisation has recently updated its recommendations on sugar intake for children and adults (World Health Organization, 2015). However, there is variation between individual countries in recommendations about sugar intake. For example, the USA (U.S. Department of Health and Human Services and U.S. Department of Agriculture, 2015) and the UK (Scientific Advisory Committee on Nutrition, 2015) recommends up to $10 \%$ and $5 \%$ of energy intake from added sugars, while Australia (National Health and Medical Research Council, 2013) recommends limiting the intake of foods and beverages containing added sugars.

Efforts to reduce sugar consumption have primarily been limited to increasing knowledge and changing attitudes (Hattersley, Irwin, King, \& Allman-Farinelli, 2009; Huffman \& West, 2007). These attempts rely on the philosophy underlying most of the existing health behavior or behavior change models (including Knowledge, Attitude and Behavior (KAB) model), that acquiring knowledge and changing attitudes influences behaviour (Baranowski, 2003). This ideology also forms the basis of many health education and health promotion programs to address behavior change. However, these health behavior models often ignore the complex interplay between factors at the individual, inter-personal and environmental levels and its influence on individuals' health behaviors (Contento, 2008; Dahlgren, 1991). In fact, there is an extensive body of literature critiquing and suggesting a tenuous association between knowledge and/or attitudes, and a range of poor health behaviors (Baranowski, 2003; Kemm, 1991; Wardle, 2000) but none for sugar intake. This is important to inform whether or not the 
47 If we are to reduce sugar intake, we need to understand the factors that influence sugar intake

48 across individual, inter-personal and environmental levels. This includes understanding whether just increasing knowledge and changing attitudes influences sugar intake practices. We aimed to bring together all available literature by conducting a systematic review with two objectives: (1) identify factors influencing adults' knowledge and attitudes about sugar; and (2) determine if there is an association between sugar intake and adults' knowledge and attitudes about sugar.

\section{METHODS}

A review protocol was developed a priori and was registered in the PROSPERO International prospective register of systematic reviews (registration number CRD42015027540) (Gupta, Braunack-Mayer, Harford, Smithers, \& Merlin, 2015). The PRISMA (Preferred Reporting Items for Systematic Reviews and Meta-Analyses) guideline was followed for reporting this systematic review (Moher, Liberati, Tetzlaff, Altman, \& The PRISMA Group, 2009) (Appendix A).

Search strategy, inclusion/exclusion criteria

The search was conducted using a range of keywords that were pilot tested and tailored for each database using relevant medical subheading $(\mathrm{MeSH})$ terms. Search terms included (knowledge* OR understanding* OR awareness OR attitude* OR perception OR perceive OR belie* OR public opinion) AND (dietary sucrose OR carbonated beverage* OR carbonated drink OR soft drink* OR fruit juice* OR soda OR pop OR sugar* OR fructose corn syrup OR added sugar OR free sugar) AND (influenc* OR shape OR effect OR impact 
OR risk OR social determinant*) OR (amount OR consum* OR intake OR level OR quantit*)

71

72

73

74

75

76

77

78

91
(Appendix B).

We conducted the search in 15 electronic databases from inception to December 2016 for all peer-reviewed studies published in the English language that included adults ( $\geq 18$ years). The databases searched included; PubMed, Scopus, Embase, Web of Science, Cumulative Index to Nursing and Allied Health Literature, PsycINFO, PsycARTICLES, Sociological abstracts, Australian Family and Society Abstracts, Dentistry and Oral Sciences Source, Database of Abstracts of Reviews of Effects, Cochrane Database of Systematic Reviews, Health Technology Assessment Database, Cochrane Central Register of Controlled Trials and The Joanna Briggs Institute Library. Study selection criteria, following a modified PICOS (population, intervention/exposure, comparison, outcome, and study context) format, were developed for each research objective (Table 1). For the first objective, the exposures included individual, inter-personal and environmental factors. Exposures such as genomics, metabolomics and any other 'omics' were excluded, as the purpose of the first objective was to identify modifiable determinants for informing future health interventions. The outcome for the first objective was knowledge and attitude about sugar (including total, added and free sugars). For the second objective, the exposure was knowledge and attitude about sugar (including total, added and free sugars) while the outcome measure was sugar intake (i.e. amount, frequency, percent energy intake from free sugars or practices such as adding table sugar or caloric sweeteners to food). 
93 Table 1: PICOS criteria for inclusion and exclusion of studies for each research objective

\begin{tabular}{ll}
\hline Inclusion criteria & Exclusion criteria \\
\hline Population & Population \\
All studies that included participants regardless & Restricted to age $\geq 18$ years and to English \\
of gender, settings, racial, ethnic, cultural or & language publications only \\
religious groups or geographical location & \\
Intervention/exposure & Intervention/exposure \\
Objective 1: Determinants of health (this & Studies with impact of genetic profile, \\
included individual, inter-personal, $\quad$ and & genomic biomarkers and/or metabolomics \\
environmental factors) & on sugar intake \\
Objective 2: Knowledge and attitude about sugar & \\
(including total, added and free sugars) & \\
Comparator(s)/ control & \\
None & Comparator(s)/ control \\
Outcome & None \\
Objective 1: Knowledge and attitude about sugar & Outcome \\
(including total, added and free sugars) & Studies that do not report relevant \\
Objective 2: Measure of sugar intake and/or & outcomes \\
practices & \\
(amount of sugar consumed or practices such as & \\
adding table sugar or sweeteners to food) & \\
Study context & \\
All studies conducted in any country around the & Study context \\
world & \\
\hline & \\
\hline
\end{tabular}


Study selection

Following the removal of duplicates and screening of titles and abstracts, full texts of potentially eligible papers were retrieved and assessed for inclusion. The reference lists of included papers were also searched for relevant articles. While AG conducted the screening of the studies for eligibility and for their full text selection, $20 \%$ of these studies were also screened by $\mathrm{JH}$. All differences regarding study inclusion were then resolved by consensus between the authors.

\section{Quality assessment and Data extraction}

The quality of included studies was assessed using the Effective Public Health Practice Project (EPHPP) quality assessment tool (Effective Public Health Practice Project, 2009). AG rated the study quality as strong, moderate or weak according to the tool criteria and $\mathrm{JH}$ verified $10 \%$ of these. Data were extracted on publication details (e.g. author's name and year of publication), characteristics of the study (e.g. study design, country, and sample size), socio-demographic profile of the population (e.g. age, gender, education, and ethnicity), relevant exposure/intervention and outcomes. LS checked the data extraction for $10 \%$ of the included papers.

\section{Data synthesis}

A meta-narrative synthesis was undertaken according to the Realist and Meta-narrative Evidence Syntheses: Evolving Standards (RAMESES) guidelines (Wong, Greenhalgh, Westhorp, Buckingham, \& Pawson, 2013). A meta-narrative synthesis is primarily driven by providing a detailed narrative account of the key dimensions of the problem under investigation. Conflicting ideas and contesting paradigms are often treated as highly important and are illustrated, explained and summarised using relevant evidence. This 
enables the readers to make informed judgements on the coherence and plausibility of the inferences. Meta-analysis was not conducted due to the presence of heterogeneity between studies in their study quality/design (predominantly cross-sectional and weak quality studies)

122 and in their ways of reporting the exposure and outcome variables. Also due to a limited 123 number of studies (such as only one study each for individual and inter-personal 124 determinants), our ability to conduct meta-regression was also limited. A meta-narrative account of the results is presented below according to the social model of health (Dahlgren, 1991).

\section{$128 \quad$ RESULTS}

129 Of 3287 articles identified (1506 for objective one and 1781 for objective two), $22\left(\mathrm{k}_{1}=14\right.$ for objective one and $\mathrm{k}_{2}=8$ for objective two) peer-reviewed studies were included in the review (Figure 1). Of these, seven were experimental studies, one was a quasi-experimental study, 13 were cross-sectional studies and one was a case study (Figure 1 and Table 2). Sixteen 133 studies were conducted in the USA, three in Europe and one each in United Kingdom, 134 Nigeria and Korea. Collectively, 17630 adults (objective one, $\mathrm{n}=7535$; objective two, $\mathrm{n}=10095$ ), with the majority being Whites, were included in the studies. Table 2 describes selected characteristics of the included studies. 
Objective1

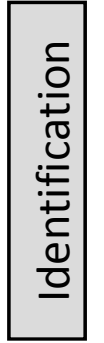

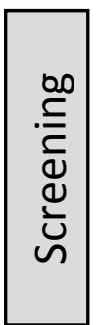

\section{Unique records screened} $k_{1}=331$

through database

searching

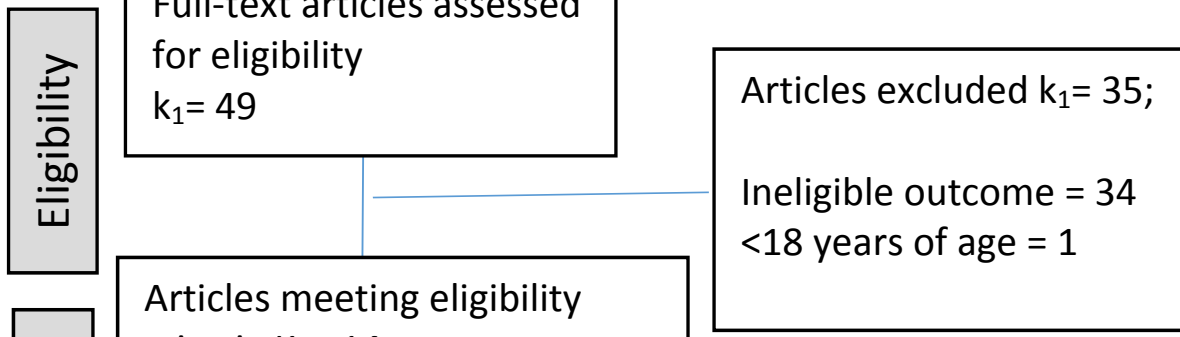

criteria $\mathrm{K}_{1}=14$;

Experimental $=7$,

Quasi-experimental $=1$

Cross-sectional $=6$

$*_{k_{1}}=1175$
Did not meet PICOS

criteria (Excluded on

title-abstract) $k_{1}=282$

Duplicates removed
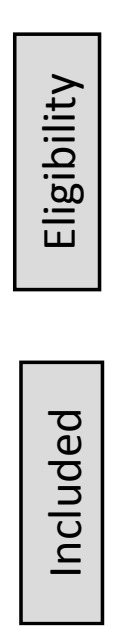

Objective2

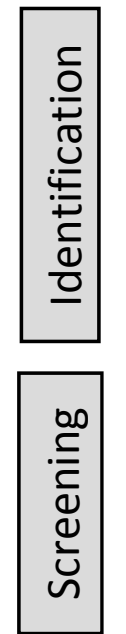

1781 records retrieved

through database

searching

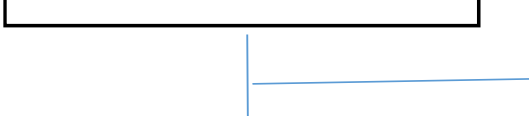

Unique records screened

$\mathrm{k}_{2}=280$

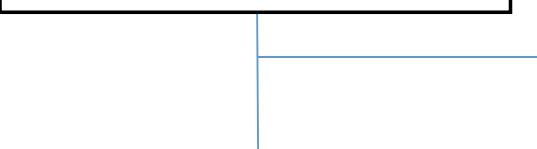

Full-text articles assessed

for eligibility

$k_{2}=77$

Articles meeting eligibility

criteria $\mathrm{k}_{2}=8$;

Cross-sectional = 7;

Case study $=1$
Duplicates removed

${ }^{*} \mathrm{k}_{2}=1501$

Did not meet PICOS

criteria (Excluded on

title-abstract) $k_{2}=203$

Articles excluded $\mathrm{k}_{2}=69$

Ineligible exposure $=33$

Ineligible outcome $=30$

$<18$ years of age $=6$

$\left({ }^{*} \mathrm{k} 1=\right.$ number of studies for objective $1 ;{ }^{*} \mathrm{k} 2=$ number of studies for objective 2$)$ 


\begin{tabular}{|c|c|c|c|c|c|}
\hline $\begin{array}{l}\text { Authors } \\
\text { (Year) }\end{array}$ & Country & $\begin{array}{l}\text { Study design and } \\
\text { sample size }\end{array}$ & Sample characteristics & $\begin{array}{l}\text { Exposure/ Intervention and } \\
\text { measurement tool used }\end{array}$ & Study findings \\
\hline $\begin{array}{l}\text { Adams et } \\
\text { al. (2014) }\end{array}$ & USA & $\begin{array}{l}\text { Experimental study } \\
\mathrm{n}=424 \\
\text { Experiment } 1: \\
\mathrm{n}=48 \\
\text { Experiment } 2: \mathrm{n}=115 \\
\text { Experiment } 3: \mathrm{n}=125 \\
\text { Experiment } 4: \mathrm{n}=136\end{array}$ & $\begin{array}{l}\text { Experiment } 1 \\
30.0 \pm 1.79 \text { years } \\
\text { Males }(\mathrm{n}=28) ; \text { Females } \\
(\mathrm{n}=20) \\
\text { Experiment } 2 \\
26.8 \pm 5.89 \text { years } \\
\text { Males }(\mathrm{n}=41) ; \text { Females } \\
(\mathrm{n}=74) \\
\text { Experiment } 3 \\
20.54 \pm 2.92 \text { years } \\
\text { Males }(\mathrm{n}=64) ; \text { Females } \\
(\mathrm{n}=61) \\
\text { Experiment } 4 \\
19.3 \pm 1.84 \text { years } \\
\text { Males ( } \mathrm{n}=92) ; \text { Females } \\
(\mathrm{n}=44)\end{array}$ & $\begin{array}{l}\text { Presentation of sugar images and } \\
\text { content information of SSBs } \\
\text { Intervention: In a concrete-sugar } \\
\text { image condition: a visual } \\
\text { representation of the amount of sugar } \\
\text { in the beverage and a caption listing } \\
\text { the number of sugar grams in the } \\
\text { beverage; in the abstract-information } \\
\text { condition: only caption was } \\
\text { provided; in a no-information } \\
\text { condition: neither of the above } \\
\text { information was provided } \\
\text { Measurement tool: Unvalidated } \\
\text { questionnaires on attractiveness and } \\
\text { selection of SSBs }\end{array}$ & $\begin{array}{l}\text { Reduced SSB attractiveness in the } \\
\text { concrete-sugar-image condition }(2.02 \\
\pm 0.87) \text { than abstract-information } \\
\text { condition }(2.56 \pm 0.68) \text {, and no- } \\
\text { information condition }(3.11 \pm 0.58) \text {. } \\
\text { Attractiveness measured on a scale } \\
\text { from } 1 \text { to } 5 \text { metric with } 1=\text { it makes } \\
\text { this beverage much less attractive and } \\
5=\text { it makes this beverage much more } \\
\text { attractive }\end{array}$ \\
\hline $\begin{array}{l}\text { Barragan et } \\
\text { al. (2014) } \\
\text { and } \\
\text { Robles et al. } \\
(2015)^{*}\end{array}$ & USA & $\begin{array}{l}\text { Cross-sectional study } \\
\mathrm{n}=1041\end{array}$ & $\begin{array}{l}\text { 18-65+ years } \\
\text { Males 51\%; Females } \\
46 \% \\
\text { Hispanic/ Latino } 40 \% \\
\text { College education } 57 \% \\
\text { Overweight or obese } \\
34 \%\end{array}$ & $\begin{array}{l}\text { Information about the number of } \\
\text { sugar packets contained in SSBs } \\
\text { Measurement tool: A validated } \\
\text { questionnaire on knowledge and } \\
\text { intention to reduce SSB intake }\end{array}$ & $\begin{array}{l}\text { High knowledge of the number of } \\
\text { sugar packs in SSB in the accurate } \\
\text { range (OR } 2.63 ; 95 \% \text { CI } 1.85,3.75 \text { ) } \\
\text { and high levels of intention to reduce } \\
\text { SSB intake }(1.95 ; 95 \% \text { CI } 1.44,2.65 \text { ) } \\
\text { among participants exposed vs non- } \\
\text { exposed to information }\end{array}$ \\
\hline
\end{tabular}




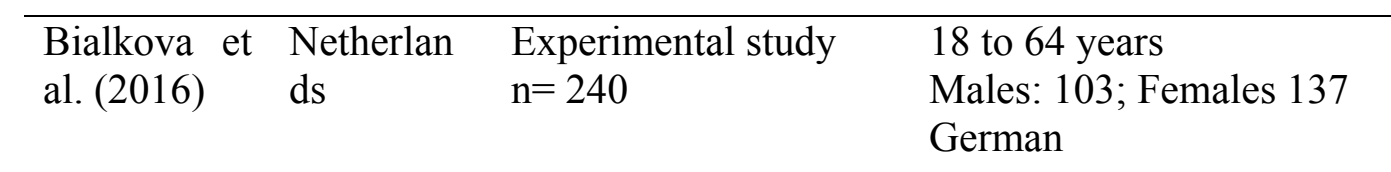

Presentation of sugar labelling and Cereal bars with label claiming 30\% advertising claims on a cereal bar. less sugar perceived as less healthy $(\mathrm{F}$

Intervention: $30 \%$ less sugar label $(2,226)=16.05, \mathrm{p}<0.0001)$.

(present vs. absent) and benefit claims (health vs. taste vs. no benefit)

Measurement tool: A unvalidated single item question on perceived healthfulness

Boles et al. USA (2014)

\section{Guidetti et UK}

al. (2012)

Jordan et al. USA

(2012)

Kessler et USA al. (1999) Cross-sectional study
$\mathrm{n}=402$

Cross-sectional study $\mathrm{n}=85$

Quasi- experimental Primary Care givers study $\mathrm{n}=507$

Cross-sectional study $\mathrm{n}=190$
Young women

18 to $65+$ years

Males 47\%; Females

$53 \%$

White $84 \%$

College education $69 \%$

College students

$18.8 \pm 0.9$ years

Males 9; Females 75
Mothers 67\%; Fathers $21 \%$

White $51 \%$

High school $36 \%$

Adults with Diabetes

30 to 74 years

Information on the amount of added sugars in SSBs, and the health impact

Measurement tool: An unvalidated questionnaire on knowledge about health problems of excessive sugar intake

Peer and parent attitudes towards sweet food intake

Measurement tool: A validated two online Implicit Association Tests, a 7-point explicit attitude scale and a questionnaire on liking for sweet snacks

Males 41\%; Females

Messages on the adverse health implications of excess SSB intake Intervention: Three media messages Measurement tool: A validated questionnaire on intention to reduce SSBs

Education by health professionals on reading food label information
Individuals living with children were more likely to agree that sugar causes health problems (OR 8.32, 95\%CI $1.05,65.84)$ than those living without children

Students attitude were more influenced by peers' negative attitudes [implicit ( $\beta$ (SE), 0.09 (.11); explicit $(0.31(0.12))]$ than parents' positive attitude [implicit $(-0.12(0.11)$; explicit $\left.\left(\begin{array}{ll}0.09 & (0.14)\end{array}\right)\right]$ for low sweet food intake

Increased intention to reduce SSB intake measured on a 1 to 7 metric with $1=$ extremely unlikely and $7=$ extremely likely:

Pre-intervention: $(5.27 \pm 1.78)$; Postintervention: $(5.74 \pm 1.63)$

$47 \%$ participants received food label education from health professionals. $73 \%$ of all participants knew sugar is a 


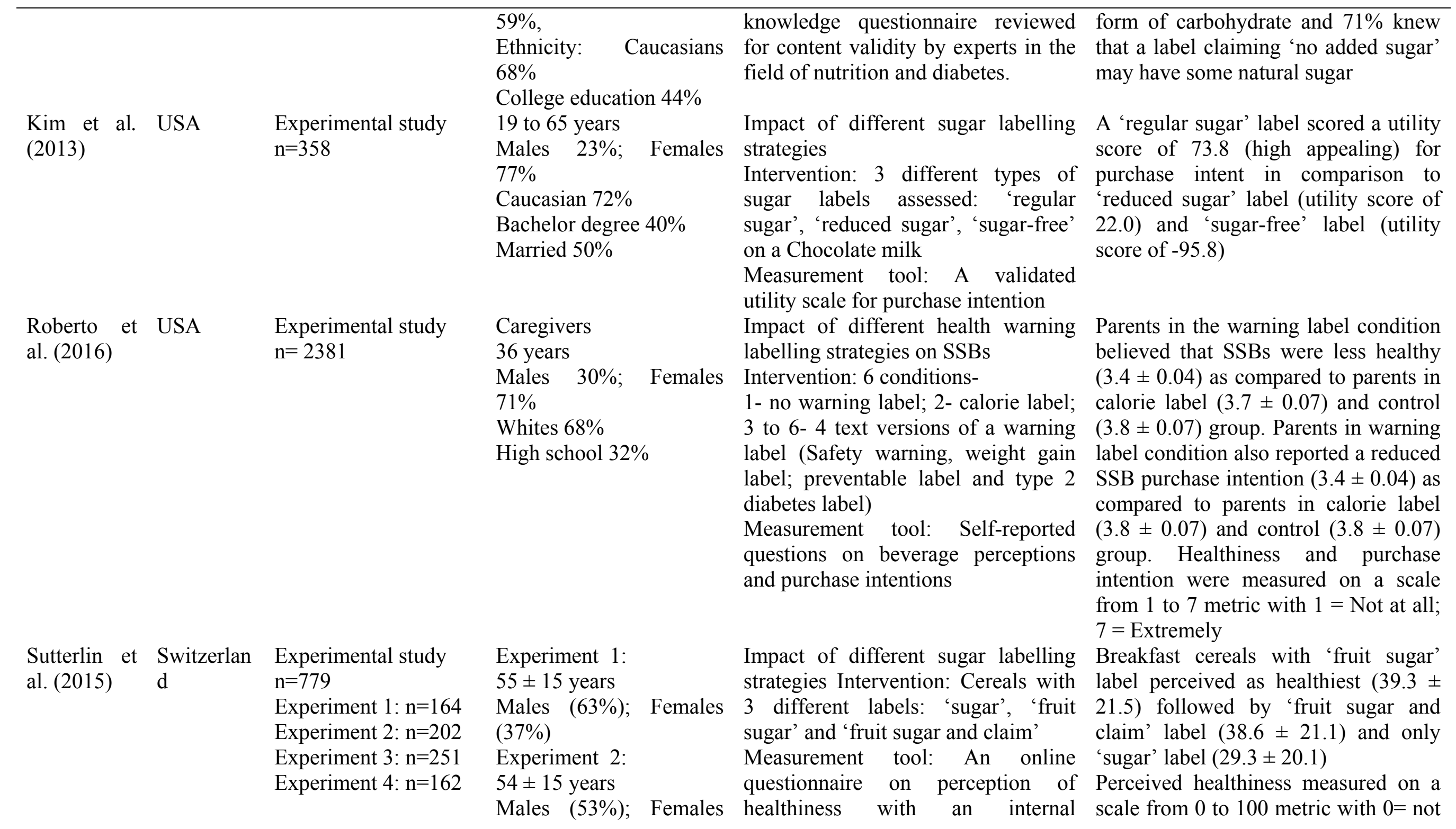




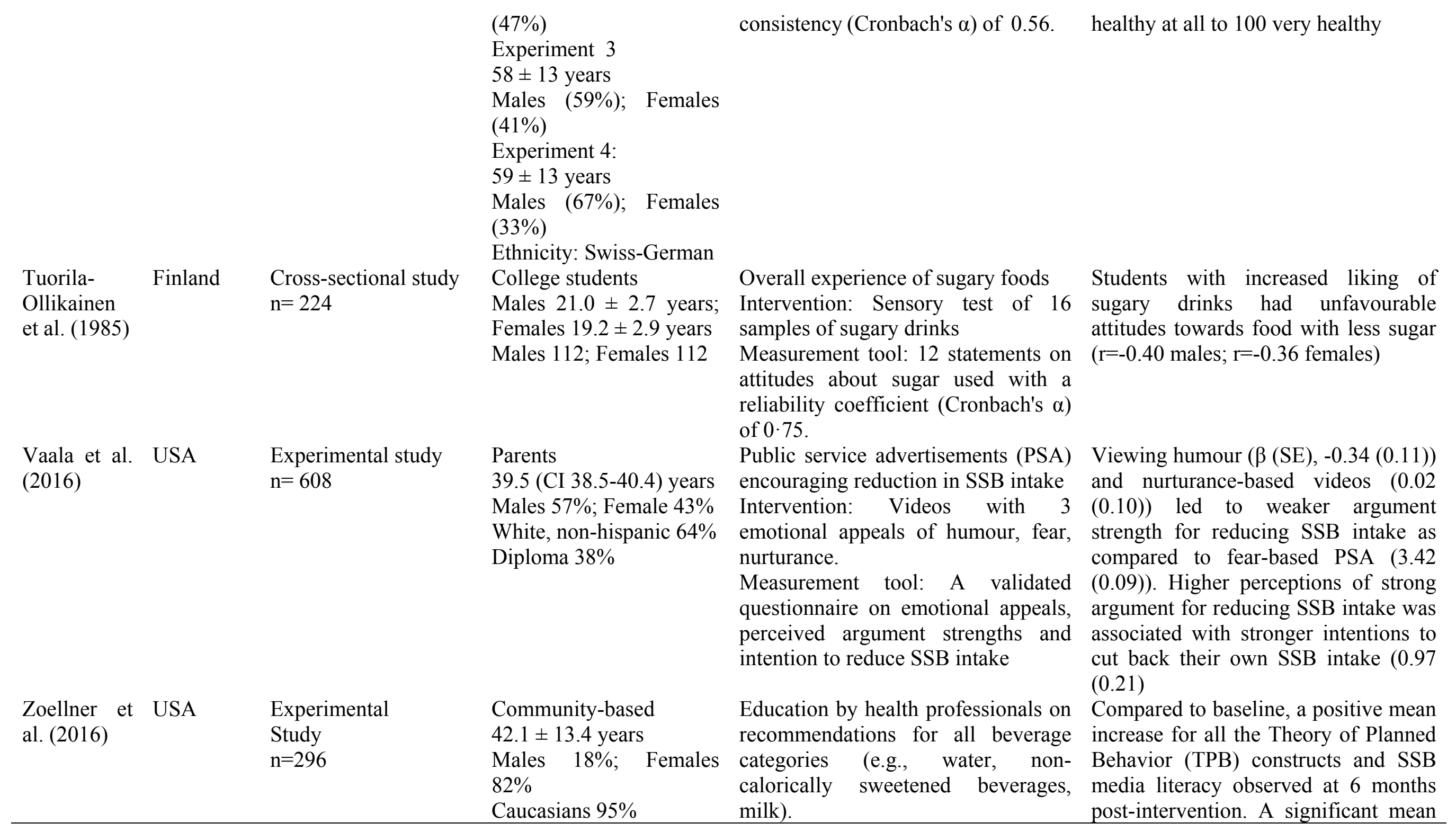


College education $70 \%$ Obesity 57\%
Intervention: Group sessions, teachback and clear communication session and interactive voice response calls.

Measurement tool: A validated questionnaire on attitudes, subjective norms, perceived behavioral control, behavioral intentions and a media literacy scale difference in TPB-SSB constructs from pre to post intervention includedTPB-SSB attitudes $0.7 \quad(0.6,0.9)$; TPB-SSB subjective norms $0.3(0.1$, $0.5)$; TPB-SSB perceived behavioral control $0.6 \quad(0.3, \quad 0.8)$; $\quad$ TPB-SSB behavioral intentions $1.0(0.6,1.3)$; SSB media literacy $8.2(6.5,9.9)$.

TBP constructs were measured on a scale from 1 to 7 with $1=$ low, $7=$ high and media literacy scale ranged from $19=$ low to $133=$ high

Objective 2: To determine if there is an association between knowledge and/or attitudes about sugar and sugar intake or practices

Fadupin et Nigeria

al. (2014)

Gase et al. USA (2014)

Hennessy et USA
Cross-sectional study $\mathrm{n}=1041$ Cross-sectional study $\mathrm{n}=376$ Undergraduate students $22.5 \pm 2.3$ years

Males 70.5\%; Females $29.5 \%$

Yoruba $81.6 \%$

Males 50.6\%; Females $45.7 \%$

Hispanic/Latino 39.8\%

College education $56.8 \%$

Overweight/obese $33.7 \%$

Caregivers
Knowledge of health implication of 8 excessive intake of SSBs and attitude

towards drinking SSBs

Measurement tool: Self-reported question on knowledge and attitudes regarding health implication of SSBs. A validated FFQ to record SSBs intake

Knowledge of daily calorie $34.2 \%$ respondents who correctly recommendations for a typical adult identified the number of calories a Measurement tool: An unvalidated typical adult consumed, on average, measure for SSB intake and self- 9.21 fewer SSBs per month than reported measure knowledge of daily respondents who did not (IRR 0.654; calorie recommendations for a 95\%CI 0.511,0.837) typical adult

Self-reported perception about Perceived healthiness was associated 


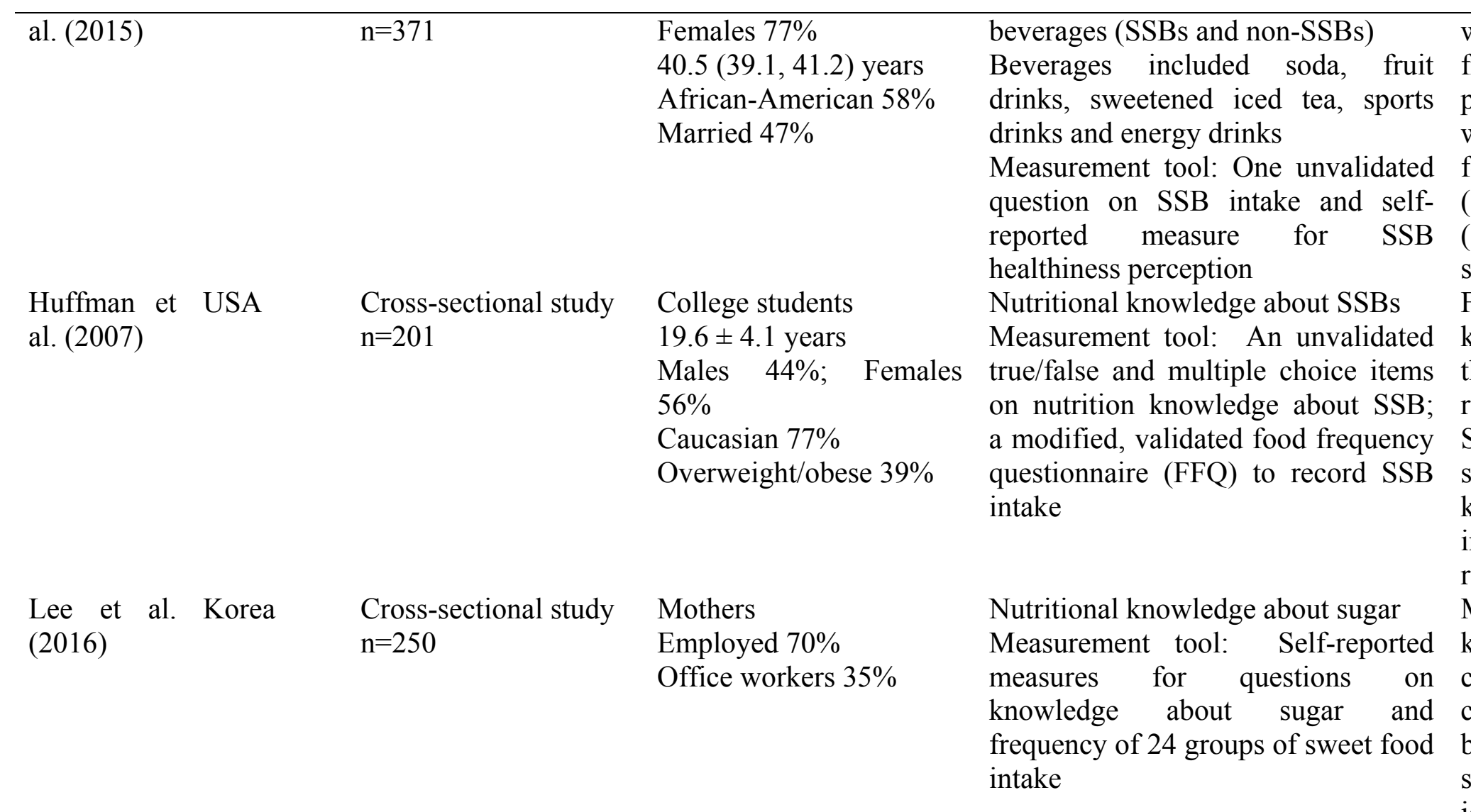

with higher intake of sweetened tea,

fruit drinks, and sports drinks among participants. A health rating of 10 would increase adults' per day intake for sweetened tea by 1.1 servings $(\beta=0.11)$; fruit drinks by 2 servings $(\beta=0.20)$ and sports drinks by 0.9 servings $(\beta=0.09)$

Females had greater nutritional knowledge about SSBs (10.2 \pm 1.9$)$ than men $(9.1 \pm 2.1)$. Students reported drinking on average $8.8 \pm 5.2$ SSBs in the previous week. No significant relationship between knowledge about SSBs and SSB intake observed (effect estimate not reported)

Mothers' with a high level of

Cross-sectional study

Employed 70\%

Office workers $35 \%$
Measurement tool: Self-reported knowledge about sugar (HLKS) measures for questions on consumed less foods high in sugar (some of which include biscuits, sweet cereal, soda, fruit juice, sports drinks, candies, caramel and ice-cream) than mothers with low knowledge about sugar (LLKS). Mean difference in HLKS and LLKS estimates as follows: Biscuits 0.6 (0.4), Sweet cereal $0.7(0.4)$, Soda 1.6 (0.1), Fruit juice $0.4(0.6)$, Sports drinks $0.6(0.5)$, Candies $1.5(0.1)$, Caramel 2.1 (0.03), Ice-cream 1.4 $(0.1)$ 


\begin{tabular}{|c|c|c|c|c|c|}
\hline $\begin{array}{l}\text { Nelson et } \\
\text { al. }(1991)\end{array}$ & USA & $\begin{array}{l}\text { Case study } \\
n=1\end{array}$ & $\begin{array}{l}41 \text { years } \\
\text { Female } \\
\text { College undergraduate }\end{array}$ & $\begin{array}{l}\text { Education about role and function of } \\
\text { sugar in diet } \\
\text { Intervention: Nutrition education } \\
\text { provided at University health centre } \\
\text { Measurement tool: An unvalidated } \\
\text { handout provided on the functions of } \\
\text { sugar in the diet. A daily dietary } \\
\text { chart used to record one teaspoon or } \\
\text { more of processed sugar. }\end{array}$ & $\begin{array}{l}\text { The average intake of processed sugar, } \\
\text { in daily servings, at baseline }(2.93 \pm \\
1.49) \text {, at treatment }(1.82 \pm 0.61) \text {, and } \\
\text { at follow-up }(3.00 \pm 1.36)\end{array}$ \\
\hline $\begin{array}{l}\text { Park et al. } \\
(2014)\end{array}$ & USA & $\begin{array}{l}\text { Cross-sectional study } \\
n=3926\end{array}$ & $\begin{array}{l}\text { 18-65 years } \\
\text { Males } 47.5 \pm 1.3 ; \\
\text { Females } 52.5 \pm 1.3 \\
\text { Whites } 69.5 \pm 1.2 \\
\text { College education } 74.4 \pm \\
2.3 \\
\text { Married } 59.4 \pm 1.4\end{array}$ & $\begin{array}{l}\text { Knowledge of health implications of } \\
\text { excessive use of SSBs } \\
\text { Measurement tool: Self-reported } \\
\text { measure for knowledge about health } \\
\text { implications of SSBs and one } \\
\text { unvalidated question on SSB intake }\end{array}$ & $\begin{array}{l}\text { Adults who were neutral (neither } \\
\text { agreed nor disagreed) or disagreed } \\
\text { regarding the influence of SSBs on } \\
\text { weight gain had } 61 \% \text { (OR } 1.61 \text {; } \\
95 \% \mathrm{CI} 1.15,2.25) \text { and } 68 \%(1.68 \text {; } \\
(0.94,3.00)) \text { higher odds of SSB } \\
\text { intake }>2 \text { times/day respectively than } \\
\text { adults who agreed }\end{array}$ \\
\hline $\begin{array}{l}\text { Zytnick et } \\
\text { al. }(2015)\end{array}$ & USA & $\begin{array}{l}\text { Cross-sectional study } \\
\mathrm{n}=3929\end{array}$ & $\begin{array}{l}\text { 18-65 years } \\
\text { Males } 48.8 \pm 1.1 ; \\
\text { Females } 51.2 \pm 1.1 \\
\text { Whites } 68.6 \pm 1.1 \\
\text { College education } 57.1 \pm \\
1.6 \\
\text { Married } 62.7 \pm 1.0\end{array}$ & $\begin{array}{l}\text { Knowledge of sugar content of sports } \\
\text { drinks } \\
\text { Measurement tool: Self-reported } \\
\text { measures for agreement of whether } \\
\text { most sports drink contain sugar and } \\
\text { an unvalidated question on SSB } \\
\text { intake }\end{array}$ & $\begin{array}{l}71 \% \text { adults agreed that sports drinks } \\
\text { contain sugar; however, no association } \\
\text { was observed among those who agreed } \\
\text { and their sports drink intake (OR } 0.78 \text {; } \\
95 \% \text { CI } 0.51,1.21 \text { ) }\end{array}$ \\
\hline
\end{tabular}

\footnotetext{
155 *Barragan et al 2014 and Robles et al 2015 analysed same cross-sectional data to report on the impact of a media campaign on knowledge and

156 attitudes of the study participants towards sugar intake.
} 
158 Table 3 summarises the quality assessments of the included studies across six domains of the EPHPP tool i.e. selection bias, study design, confounding, blinding, data collection,

160 withdrawal/ drop-outs. Collectively, a majority of the studies $\left(\mathrm{k}^{1}=16\right)$ had their study samples 161 likely to be representative of the target population. All the experimental and quasiexperimental studies scored a strong rating for their study design while other cross-sectional studies and a case study were rated as weak. However, almost half of the studies $(\mathrm{k}=11)$ irrespective of their study designs, controlled for potential confounding, resulting in a strong rating on that domain. Most studies $(\mathrm{k}=15)$ scored a moderate rating for the blinding domain due to either reporting of partial blinding or no reporting at all in their studies. Twelve studies either reported the internal consistency of the tool used or used a previously validated data collection tool, resulting in a strong to moderate rating. The final domain of the tool, referring to the percentage of participants completing the study was not applicable for most of the studies $(\mathrm{k}=16)$ and therefore scored a week or moderate rating. Only five studies (Jordan, Piotrowski, Bleakley, \& Mallya, 2012; Roberto, Wong, Musicus, \& Hammond, 2016; Sutterlin \& Siegrist, 2015; Vaala, Bleakley, Hennessy, \& Jordan, 2016; Zoellner et al., 2016) scored an overall moderate rating.

\footnotetext{
${ }^{1} \mathrm{k}=$ number of studies
} 
Table 3: Study quality assessments using EPHPP tool

\begin{tabular}{|c|c|c|c|c|c|c|c|}
\hline Author-Year & $\begin{array}{l}\text { Selection Bias } \\
\text { (Overall) }\end{array}$ & $\begin{array}{l}\text { Study Design } \\
\text { (Overall) }\end{array}$ & $\begin{array}{l}\text { Confounding } \\
\text { (Overall) }\end{array}$ & $\begin{array}{l}\text { Blinding } \\
\text { (Overall) }\end{array}$ & $\begin{array}{l}\text { Data Collection } \\
\text { (Overall) }\end{array}$ & $\begin{array}{l}\text { Withdrawal } \\
\text { dropouts (Overall) }\end{array}$ & $\begin{array}{l}\text { Global Score } \\
\text { (Overall)* }\end{array}$ \\
\hline \multicolumn{8}{|l|}{ OBJECTIVE 1} \\
\hline Adams et al. (2014) & Strong & Strong & Weak & Moderate & Weak & Weak & Weak \\
\hline Barragan et al. (2014) & Weak & Weak & Strong & Weak & Moderate & Weak & Weak \\
\hline Bialkova et al. (2016) & Weak & Strong & Weak & Moderate & Weak & Moderate & Weak \\
\hline Boles et al. (2014) & Weak & Weak & Strong & Moderate & Weak & Weak & Weak \\
\hline Guidetti et al. (2012) & Moderate & Weak & Weak & Moderate & Strong & Moderate & Weak \\
\hline Jordan et al. (2012) & Strong & Strong & Weak & Moderate & Moderate & Moderate & Moderate \\
\hline Kessler et al. (1999) & Strong & Weak & Weak & Weak & Moderate & Moderate & Weak \\
\hline Kim et al. (2013) & Strong & Strong & Weak & Weak & Moderate & Moderate & Weak \\
\hline Roberto et al. (2016) & Moderate & Strong & Strong & Moderate & Weak & Moderate & Moderate \\
\hline Robles et al. (2015) & Weak & Weak & Strong & Weak & Moderate & Weak & Weak \\
\hline Sutterlin et al. (2015) & Moderate & Strong & Moderate & Moderate & Moderate & Weak & Moderate \\
\hline Tuorila-Ollikainen et al. (1985) & Moderate & Weak & Weak & Moderate & Moderate & Moderate & Weak \\
\hline Vaala et al. (2016) & Moderate & Strong & Strong & Moderate & Strong & Weak & Moderate \\
\hline Zoellner et al. (2016) & Moderate & Strong & Strong & Weak & Moderate & Moderate & Moderate \\
\hline \multicolumn{8}{|l|}{ OBJECTIVE 2} \\
\hline Fadupin et al. (2014) & Weak & Weak & Weak & Weak & Moderate & Moderate & Weak \\
\hline Gase et al. (2014) & Weak & Weak & Strong & Moderate & Moderate & Moderate & Weak \\
\hline Hennessy et al. (2015) & Moderate & Weak & Strong & Moderate & Weak & Moderate & Weak \\
\hline Huffman et al. (2007) & Strong & Weak & Weak & Moderate & Weak & Moderate & Weak \\
\hline Lee et al. (2016) & Moderate & Weak & Strong & Weak & Weak & Moderate & Weak \\
\hline Nelson et al. (1991) & Strong & Weak & Weak & Moderate & Weak & Moderate & Weak \\
\hline Park et al. (2014) & Weak & Weak & Strong & Moderate & Weak & Moderate & Weak \\
\hline Zytnick et al. (2015) & Weak & Weak & Strong & Moderate & Weak & Moderate & Weak \\
\hline
\end{tabular}

* Strong (no weak ratings), Moderate (one weak rating), Weak (two or more weak ratings) 
Factors influencing adults' knowledge and attitudes about sugar (Objective 1)

We classified studies into three domains: individual determinants, inter-personal determinants and environmental determinants.

Individual determinants: A single cross-sectional study was identified and included under the individual determinants (Tuorila-Ollikainen \& Mahlamaki-Kultanen, 1985). This study, conducted among 19-21 year old Finnish college students, reported correlations between attitudinal and experience-based factors related to sugar intake. The participants rated the pleasantness of sweetness in drink samples with two sweetness levels and their attitudes towards sugar using 12 statements. The study found that students with increased liking of sugary drinks had unfavourable attitudes towards food with less sugar $(r=-0.40$ males; $\mathrm{p}<0.001$ and $\mathrm{r}=-0.36$ females; $\mathrm{p}<0.001)$. The study did not adjust for some important confounders such as socio-demographic characteristics of the participants that may have affected the study findings.

Inter-personal determinants: A single cross-sectional study was included under the interpersonal determinants (Guidetti, Conner, Prestwich, \& Cavazza, 2012). This study of 85 college students found that individuals' preferences for sweet foods were influenced by their peers' negative attitudes (implicit $\beta, 0.13 \mathrm{SE}(0.11)$; explicit $\beta, 0.35 \mathrm{SE}(0.12)$ ) but not their parents' attitudes (implicit $\beta,-0.16 \mathrm{SE}$ (0.11); explicit $\beta, 0.09$ SE (0.14)). While this study used a validated scale to measure attitudes (implicit and explicit), the study was small and the sample was mainly females. Furthermore, the confounding variables adjusted for in this analysis were limited to the effect of cohabitation with parent or peers and duration of friendship. Other potential confounders, such as place of residence, school type (private or 
public), time spent at home and school, and childhood dietary practices, were not included which may have affected the study findings.

Environmental determinants: Twelve studies investigated the influence of media tools (including campaigns and advertising materials), health professionals' advice and sugar labelling strategies on knowledge and attitudes about sugar.

Media tools had positive impacts on knowledge and attitudes about the importance of reducing the consumption of sugar from food and beverages (Barragan et al., 2014; Boles, Adams, Gredler, \& Manhas, 2014; Jordan et al., 2012; Robles et al., 2015; Vaala et al., 2016). A moderate quality experimental study (Vaala et al., 2016) was conducted among parents who consumed an average of $2.8 \mathrm{SSB}$ servings/day $(\mathrm{SD}=2.9)$. The study aimed to identify parents' reactions to anti-SSB messages to inform the design of future media messages. The study found that adults who viewed fear-based advertisements about reducing SSB intake had a stronger emotional and cognitive reaction than those who viewed humorous or nurturing advertisements. The fear-based advertisements stressed the health risks associated with SSB consumption. The study also reported an association between participants' perceptions of argument strength ('defined as the extent to which participants perceived sound arguments for reducing SSB consumption') and stronger intentions about reducing SSB intake $[\beta(\mathrm{SE})$, $0.97(0.21)]$, following the viewing of fear-based advertisements. Similar intentions to reduce SSB intake were also observed in another moderate quality quasi-experimental study (Jordan et al., 2012) conducted among a sample of 507 caregivers of young children. This study found an increase $(p<0.05)$ in the intention to reduce SSB intake among caregivers post exposure to messages $(5.74 \pm 1.78)$ than pre-exposure $(5.27 \pm 1.78)$ on the adverse health effects of SSBs. 
227 Similar positive impacts of being exposed to a campaign focussing on the importance of reducing the consumption of SSBs were also reported in two cross-sectional studies conducted in the US (Barragan et al., 2014; Robles et al., 2015). One of them (Barragan et al., 2014) reported more than twice the likelihood of correctly reporting the quantity of sugar in a soda drink (OR 2.63, 95\%CI: 1.85, 3.75) among participants exposed to the campaign compared with those not exposed to the campaign. The second (Robles et al., 2015) found that moderate consumers (1-6 sodas/week) were nearly twice as likely to reduce SSB intake (OR 1.95, 95\%CI 1.44, 2.65) after exposure to the campaign, compared with heavy consumers ( $\geq 1$ soda/day). Though both these cross-sectional studies analysed the same data and had a large sample of adults $(\mathrm{n}=1041)$, both may be at risk of selection bias as the sample was recruited from selected public transit locations. A similar positive finding was also observed in yet another small cross-sectional study (Boles et al., 2014) where parents exposed to messages on the adverse health effects of SSBs were more likely to agree that sugar causes health problems (OR 8.32, 95\%CI 1.05, 65.84) if they had children at home than those with no children at home. Due to the wide confidence intervals, the precision of the findings are limited.

A moderate quality experimental study (Zoellner et al., 2016) assessed the impact of receiving information through health professionals (research staff and students) on participants' knowledge and attitudes about sugar. They delivered a range of sessions for 6 months, focusing on the recommendations for various beverage intake (e.g., water, SSBs, and milk). The study found that the intervention had a positive impact on participants' attitudes, perceptions, and intentions towards reducing SSB intake. The study used validated measures and had an appropriately powered sample $(\mathrm{n}=296)$ for detecting a small effect size of 0.34 for 
the effects of intervention over 6 months. A similar cross-sectional study was conducted

252

253

254

255

256

257

258

259

260

261

262

263

264

265

266

267

268

269

270

271

272

273

274
(Kessler \& Wunderlich, 1999) where 47\% participants received food label education from their health professionals (such as nurse, diabetes educator, or dieticians). Seventy-three percent of all participants knew sugar is a form of carbohydrate and $71 \%$ knew that label claiming 'no added sugar' may have some natural sugar. However, no association was assessed between receiving education and change in knowledge.

The remaining five experimental studies (Adams, Hart, Gilmer, Lloyd-Richardson, \& Burton, 2014; Bialkova, Sasse, \& Fenko, 2016; Kim, Lopetcharat, \& Drake, 2013; Roberto et al., 2016; Sutterlin \& Siegrist, 2015) explored whether products with sugar labels influence attitudes towards sugar. These studies had mixed results with three (Adams et al., 2014; Bialkova et al., 2016; Roberto et al., 2016) reporting positive effects of sugar labels on attitudes towards reduced SSB consumption, while the other two (Kim et al., 2013; Sutterlin $\&$ Siegrist, 2015) did not find such effects. The presence of a 'less than $30 \%$ sugar' label; a health-warning label ('drinking beverages with added sugar[s] contributes to obesity, diabetes, and tooth decay'); and a pictorial image of quantity of sugar in SSBs, all generated positive attitudes to reduce purchase intention and consumption of SSBs. In other words, across diverse samples in different countries (US and Netherlands), these interventions resulted in an increase in the perception of sugary products as unhealthy. By contrast, two studies (Kim et al., 2013; Sutterlin \& Siegrist, 2015) that aimed to assess the participants' perceptions (with no intention to raise awareness) towards different sugar labels did not find such effects. One of them (Sutterlin \& Siegrist, 2015) reported that participants perceived cereals with a 'fruit sugar' label $(39.3 \pm 21.5)$ to be healthier (a high score) $(\mathrm{p}<0.05)$ than cereals with 'sugar' label only $(29.3 \pm 20.1)$. The other (Kim et al., 2013) found chocolate 
milk with a 'regular sugar' label to be more appealing among consumers compared to the 'reduced sugar' or 'sugar-free' label.

Association between adults' knowledge and attitudes about sugar and sugar intake (Objective 2)

We divided the studies into two groups: those that focused on the association between knowledge about sugar and sugar intake; and those that focused on the association between attitudes towards sugar and sugar intake.

Six cross-sectional studies (Fadupin, Ogunkunle, \& Gabriel, 2014; Gase, Robles, Barragan, \& Kuo, 2014; Huffman \& West, 2007; Lee \& Joo, 2016; Park, Onufrak, Sherry, \& Blanck, 2014; Zytnick, 2015) and one case-study (Nelson \& Hekmat, 1991) investigated the association between knowledge about sugar and sugar intake. Three of these cross-sectional studies (Gase et al., 2014; Lee \& Joo, 2016; Park et al., 2014) reported an association between increasing knowledge about sugar and reduced consumption of food and beverages with sugar. These findings were consistent across studies conducted in two different countries (Korea and US), with varying sample sizes $(n=250,1041$ and 3926) and using different data collection tools. However, the findings in these studies must be viewed in light of their limitations, including convenience sampling, single measures of nutritional knowledge, and not adjusted for potential confounders. In contrast, two studies, (Huffman \& West, 2007; Zytnick, 2015) conducted in the US using self-reported data among college students $(n=205)$ and adults $(n=3929)$ found no association between greater knowledge about sugar and reduced SSB intake. Two other studies (Fadupin et al., 2014; Nelson \& Hekmat, 1991) although proposed to investigate an association between knowledge and sugar intake, only reported separate prevalence estimates for the measures. 
301 Only one (Hennessy, Bleakley, Piotrowski, Mallya, \& Jordan, 2015) cross-sectional study assessed the association between attitude towards sugar and sugar intake. This study, conducted among African-American/ Non-African American female caregivers of young children, found that caregivers who perceived sugary beverages to be healthy reported a high intake of sugary beverages (see estimates in Table 2). However, the authors stated that the study was unable to determine the causal direction of the association between health rating and sugary beverage consumption. This study may also be at a risk of respondent burden due to a long beverage list and as the sample was restricted to African-American/ Non-African American caregivers its findings are non-generalizable to the larger population of American parents.

\section{DISCUSSION}

The purpose of this review was twofold: first, to identify factors influencing adults' knowledge and attitudes about sugar and, second, to assess the association between knowledge and attitudes about sugar and sugar intake. Firstly, a range of factors influenced adults' knowledge and attitudes about sugar, but only to a certain extent. These factors included individual (liking of sugary food), inter-personal (attitudes of peers) and environmental factors (media tools, health professionals and labelling strategies). Secondly, the evidence in these studies was not adequate to establish an association between knowledge and attitudes about sugar and sugar intake. Except for five moderate quality studies identified for the first objective of the review, all studies were of weak quality, mainly due to problems with study design, sampling strategies, data collection tools and potential confounding. 
324 Among the studies reviewed under the first objective, only two studies described the relationship between individual and inter-personal factors and adults' attitudes towards sugar intake. One study found that increased liking for sugary food negatively influenced young people's perceptions, beliefs, and intentions to reduce sugar intake in adulthood. The other study found a greater influence of peers in determining the adolescents' preference for sweet food than parents. A recent review (Guidetti \& Cavazza, 2010) has found that parents and peers are critical to young people's attitudes towards food, but that the mechanisms of influence are quite different. For instance, parental influence may occur through genetic transmission, restriction on certain foods and modelling. Peer influence may occur through strength of friendship and social pressure. Research has also shown that parents are more influential in long-term decisions such as education and future planning whereas peers are influential in everyday decisions such as hobbies and, to some extent, food consumption (Sebald, 1980). Parental influence is often limited after adolescence and a greater similarity to peers is often observed in the attitudes relating food and other behaviors (Becker \& Curry, 2014; Sawka, McCormack, Nettel-Aguirre, \& Swanson, 2015; Seo \& Huang, 2012). This is consistent with the study in this review that found stronger peer influence in an adolescent population.

In this review, evidence from the moderate quality studies shows that disseminating information about recommended intakes and health implications of sugar through a variety of media tools increases knowledge and generates positive attitudes towards reducing sugar consumption. These strategies strengthened participants' perceptions of the health risks posed by SSB intake, thereby increasing the likelihood of behavior change. Simple, meaningful but confronting images and labels appeared to improve knowledge and promote positive attitudes toward reducing sugar intake. These findings suggest that, at a population level, using a 
variety of media tools in conjunction with advice from health professionals may change knowledge and attitudes. Similar outcomes have been reported for nutrition and other healthrelated interventions (Beaudoin, Fernandez, Wall, \& Farley, 2007; Hammond, Fong, McDonald, Brown, \& Cameron, 2004; Robinson, 1997; Wakefield, Loken, \& Hornik, 2010; Witte \& Allen, 2000).

The findings for the second part of our review are consistent with other literature on the limited effectiveness of theories and models of behaviour and behaviour change that focus on knowledge and attitudes (Baranowski, 2003; Kemm, 1991). Overall, we found weak and inconsistent associations between knowledge and attitudes, and sugar intake. The association is clearly more complex than that assumed by those health behaviour models that focus on knowledge and attitude. Associations between knowledge and attitudes and behavior change are likely to be restricted to specific populations such as highly motivated groups or individuals caring for young children (Baranowski, 2003), which was not the case found in our review. Furthermore as the circumstances in which people live and work have a profound influence on their health and health behaviors (Wilkinson, 2003), a focus exclusively on knowledge and attitudes alone is unlikely to explain behavior change. The physical environment, such as access and availability to food; the economic environment, in which the resources to purchase and the price of food matter; the social environment, in which social and cultural factors inform consumption patterns; and the political environment, where national or local policies influence food availability, all influences behavior (Kearney, 2010; Phelan, Link, \& Tehranifar, 2010).

372 We conclude that knowledge and attitudes are only two among the many factors that may 373 influence sugar intake. Sugar intake is shaped by a range of social, environmental and 
political factors. If the problem of consuming sugar above the recommended levels is to be resolved, we need to address the causes of sugar intake beyond individual factors.

\section{Strengths and limitations}

A thorough search conducted in 15 different databases, using well-defined selection criteria and a systematic synthesis of the data, made our review process rigorous and robust. However, the review has some limitations. Firstly, the review excluded non-English language and unpublished literature, which may have led to exclusion of relevant studies. Second, our search terms may have limited our scope in identifying relevant literature. Third, heterogeneity in study characteristics, study designs, data collection tools and reporting of outcome measures limited our ability to conduct a quantitative synthesis. The quality of the majority of the included studies was generally weak across different quality domains. The tools available for measuring nutrition knowledge are both limited and contentious (Parmenter \& Wardle, 1999); therefore, we did not set conditions for the exclusion of papers using invalidated tools a priori, which explains the inclusion of studies with unvalidated/ unreliable data collection tools.

\section{CONCLUSION}

The role of knowledge and attitudes in determining health behaviors is much debated, and this is clearly also the case for sugar intake. This review highlights the paucity of evidence on factors influencing adults' knowledge and attitudes about sugar and the association of knowledge and attitudes with sugar intake. From the review, it is evident that the impact of knowledge and attitudes on sugar intake is limited, even though a range of determinants influences knowledge and attitude towards sugar to a certain extent. We need to take a holistic approach to consider the other factors (socio-demographic, cultural, social structure, 
economic conditions, taxation, trade, marketing etc.) that influence sugar intake in all our

400

401

402

403

404

405

406

407

408

409

410

411

412

413

414

415

416

417

418

419

420

421

422

423

attempts to reduce sugar intake. A better understanding of the causal pathways is likely to help public health professionals and policy makers to develop appropriate public health interventions and policies to tackle our high levels of sugar intake.

\section{Role of funding sources}

AG receives a scholarship from Adelaide Scholarships International. ABM is a recipient of Healthy laws grant funded by Australian National Preventive Health Agency and is a professor at the University of Adelaide.

\section{Contributors}

All authors equally contributed to develop both the systematic review protocol and the systematic review manuscript. Author Gupta conducted the review process, reviewed all articles, and wrote all sections of the manuscript. Authors Harford and Smithers independently screened the articles and conducted the quality assessments. All authors provided feedback and suggestions on multiple drafts of the manuscript and all have approved the final manuscript.

\section{Declaration of interest}

The authors declare no conflicts of interest.

\section{LEGENDS}

\section{Figures legends}

Figure 1. PRISMA flow diagram of the literature search process

\section{Table legends}


424 Table 1. PICOS criteria for inclusion and exclusion of studies

425 Table 2. Characteristics of the included studies

426 Table 3. Study quality assessments using EPHPP tool

427 APPENDICES

428 Appendix A: PRISMA 2009 Checklist

429 Appendix B: Search strategy following PRISMA guidelines:

430 (a) Objective 1: To identify factors influencing adults' knowledge and attitudes about sugar.

431 (b) Objective 2: To determine if there is an association between adults' knowledge and 432 attitudes about sugar and sugar intake 
Adams, J. M., Hart, W., Gilmer, L., Lloyd-Richardson, E. E., \& Burton, K. A. (2014). Concrete images of the sugar content in sugar-sweetened beverages reduces attraction to and selection of these beverages. Appetite, 83, 10-18. doi: 10.1016/j.appet.2014.07.027

Baranowski, T., Cullen, KW., Nicklas, T., Thompson, D., Baranowski, J. (2003). Are current health behavioral change models helpful in guiding prevention of weight gain efforts? Obesity Research, Suppl:23S-43S.

Barragan, N. C., Noller, A. J., Robles, B., Gase, L. N., Leighs, M. S., Bogert, S.et al. (2014). The "sugar pack" health marketing campaign in Los Angeles County, 2011-2012. Health Promotion Practice, . 15(2), 208-216. doi: 10.1177/1524839913507280

Beaudoin, C. E., Fernandez, C., Wall, J. L., \& Farley, T. A. (2007). Promoting healthy eating and physical activity short-term effects of a mass media campaign. American Journal of Preventive Medicine, 32(3), 217-223. doi: 10.1016/j.amepre.2006.11.002

Becker, S. J., \& Curry, J. F. (2014). Testing the Effects of Peer Socialization versus Selection on Alcohol and Marijuana Use among Treated Adolescents. Substance use \& misuse, 49(3), 234-242. doi: 10.3109/10826084.2013.824479

Bialkova, S., Sasse, L., \& Fenko, A. (2016). The role of nutrition labels and advertising claims in altering consumers' evaluation and choice. Appetite, 96, 38-46. doi: 10.1016/j.appet.2015.08.030

Boles, M., Adams, A., Gredler, A., \& Manhas, S. (2014). Ability of a mass media campaign to influence knowledge, attitudes, and behaviors about sugary drinks and obesity. Preventive Medicine, 67, S40-45 41p. doi: 10.1016/j.ypmed.2014.07.023

Contento, I. R. (2008). Nutrition education: linking research, theory, and practice. Asia Pacific Journal of Clinical Nutrition, 17 Suppl 1, 176-179.

Dahlgren, G., Whitehead, M. (1991). Policies and strategies to promote social equity in health Stockholm (Mimeo).

Effective Public Health Practice Project. (2009). Quality assessment tool for quantitative studies.

Fadupin, G. T., Ogunkunle, M. O., \& Gabriel, O. O. (2014). Knowledge, attitude and consumption pattern of alcoholic and sugar sweetened beverages among undergraduates in a Nigerian institution. African Journal of Biomedical Research, 17(2), 75-82.

Gase, L. N., Robles, B., Barragan, N. C., \& Kuo, T. (2014). Relationship between nutritional knowledge and the amount of sugar-sweetened beverages consumed in Los Angeles County. Health Education \& Behavior, 41(4), 431-439.

Gibson, S. (2008). Sugar-sweetened soft drinks and obesity: a systematic review of the evidence from observational studies and interventions. Nutrition Research Reviews, 21(2), 134-147. doi: $10.1017 /$ s0954422408110976

Guidetti, M., \& Cavazza, N. (2010). Social influence in the formation of food preferences. Psicologia Sociale, 5, 357-383.

Guidetti, M., Conner, M., Prestwich, A., \& Cavazza, N. (2012). The transmission of attitudes towards food: twofold specificity of similarities with parents and friends. British journal of health psychology, 17(2), 346-361.

Gupta, A., Braunack-Mayer, A., Harford, J., Smithers, L. G., \& Merlin, T. (2015). Dietary sugar knowledge and attitudes among adults and their relation to sugar intake and practices: a systematic review protocol. PROSPERO: CRD42015027540. doi: http://www.crd.york.ac.uk/PROSPERO/display record.asp?ID=CRD42015027540

Hammond, D., Fong, G. T., McDonald, P. W., Brown, K. S., \& Cameron, R. (2004). Graphic Canadian cigarette warning labels and adverse outcomes. Evidence from Canadian smokers. American Journal of Public Health, 94(8), 1442-1445. 
Hattersley, L., Irwin, M., King, L., \& Allman-Farinelli, M. (2009). Determinants and patterns of soft drink consumption in young adults: a qualitative analysis. Public Health Nutrition,. 12(10), 1816-1822. doi: $10.1017 / \mathrm{s} 136898000800462 x$

Hennessy, M., Bleakley, A., Piotrowski, J. T., Mallya, G., \& Jordan, A. (2015). Sugar-Sweetened Beverage Consumption by Adult Caregivers and Their Children: The Role of Drink Features and Advertising Exposure. Health Education \& Behavior, 42(5), 677-686. doi: $10.1177 / 1090198115577379$

Huffman, L., \& West, D. S. (2007). Readiness to change sugar sweetened beverage intake among college students. Eating Behaviors, 8(1), 10-14.

Imamura, F., O'Connor, L., Ye, Z., Mursu, J., Hayashino, Y., Bhupathiraju, S. N.et al. (2015). Consumption of sugar sweetened beverages, artificially sweetened beverages, and fruit juice and incidence of type 2 diabetes: systematic review, meta-analysis, and estimation of population attributable fraction. British Medical Journal, 351, h3576. doi: 10.1136/bmj.h3576

Jordan, A., Piotrowski, J. T., Bleakley, A., \& Mallya, G. (2012). Developing Media Interventions to Reduce Household Sugar-Sweetened Beverage Consumption. The ANNALS of the American Academy of Political and Social Science, 640(1), 118-135. doi: 10.1177/0002716211425656

Kearney, J. (2010). Food consumption trends and drivers. Philosophical Transactions of the Royal Society B: Biological Sciences, 365(1554), 2793-2807. doi: 10.1098/rstb.2010.0149

Kemm, J. (1991). Health education and the problem of knowledge. Health Promotion International, 6(4), 291-296. doi: 10.1093/heapro/6.4.291

Kessler, H., \& Wunderlich, S. M. (1999). Relationship between use of food labels and nutrition knowledge of people with diabetes. The Diabetes educator, 25(4), 549-559.

Kim, M. K., Lopetcharat, K., \& Drake, M. A. (2013). Influence of packaging information on consumer liking of chocolate milk. [Article]. Journal of Dairy Science, 96(8), 4843-4856. doi: 10.3168/jds.2012-6399

Lee, Y., \& Joo, N. (2016). The awareness level and needs for education on reducing sugar consumption among mothers with preschool children. Nutrition Research Practice., 10(2), 229-236. doi: 10.4162/nrp.2016.10.2.229

Moher, D., Liberati, A., Tetzlaff, J., Altman, D., \& The PRISMA Group. (2009). Preferred reporting items for systematic reviews and meta-analyses: the PRISMA statement. Annals of Internal Medicine, 151(4), 264-269.

National Health and Medical Research Council. (2013). Australian Dietary Guidelines Canberra.

Nelson, L. J., \& Hekmat, H. (1991). Promoting healthy nutritional habits by paradigmatic behavior therapy. Journal of Behavior Therapy and Experimental Psychiatry, 22(4), 291-298.

Park, S., Onufrak, S., Sherry, B., \& Blanck, H. M. (2014). The Relationship between Health-Related Knowledge and Sugar- Sweetened Beverage Intake among US Adults. Faseb Journal, 27.

Parmenter, K., \& Wardle, J. (1999). Development of a general nutrition knowledge questionnaire for adults. European Journal of Clinical Nutrition, 53. doi: 10.1038/sj.ejcn.1600726

Phelan, J. C., Link, B. G., \& Tehranifar, P. (2010). Social conditions as fundamental causes of health inequalities: theory, evidence, and policy implications. Journal of Health and Social Behavior., 51 Suppl, S28-40. doi: 10.1177/0022146510383498

Roberto, C. A., Wong, D., Musicus, A., \& Hammond, D. (2016). The Influence of Sugar-Sweetened Beverage Health Warning Labels on Parents' Choices. Pediatrics, 137(2), 1-10. doi: 10.1542/peds.2015-3185

Robinson, T. N., Killen, J. D. (1997). Do cigarette warning labels reduce smoking? Paradoxical effects among adolescents. Archives of Pediatrics \& Adolescent Medicine, 151(3), 267-272.

Robles, B., Blitstein, J. L., Lieberman, A. J., Barragan, N. C., Gase, L. N., \& Kuo, T. (2015). The relationship between amount of soda consumed and intention to reduce soda consumption among adults exposed to the Choose Health LA 'Sugar Pack' health marketing campaign. Public Health Nutrition., 18(14), 2582-2591. doi: 10.1017/s1368980014003097 
Sawka, K. J., McCormack, G. R., Nettel-Aguirre, A., \& Swanson, K. (2015). Associations between aspects of friendship networks and dietary behavior in youth: Findings from a systematized review. Eating Behaviors, 18, 7-15. doi: 10.1016/j.eatbeh.2015.03.002

Scientific Advisory Committee on Nutrition. (2015). Carbohydrates and Health London (UK): T. S. O. Limited. Retrieved from https://www.gov.uk/government/publications/sacn-carbohydratesand-health-report

Sebald, H., White, B. . (1980). Teenagers' divided reference groups: Uneven alignment with parents and peers. Adolescence, 15, 979-984.

Seo, D. C., \& Huang, Y. (2012). Systematic review of social network analysis in adolescent cigarette smoking behavior. Journal of School Health, 82(1), 21-27. doi: 10.1111/j.17461561.2011.00663.x

Sheiham, A., \& James, W. P. (2014). A reappraisal of the quantitative relationship between sugar intake and dental caries: the need for new criteria for developing goals for sugar intake. $B M C$ Public Health, 14, 863. doi: 10.1186/1471-2458-14-863

Sutterlin, B., \& Siegrist, M. (2015). Simply adding the word "fruit" makes sugar healthier: The misleading effect of symbolic information on the perceived healthiness of food. Appetite, 95, 252-261.

Te Morenga, L., Mallard, S., \& Mann, J. (2013). Dietary sugars and body weight: systematic review and meta-analyses of randomised controlled trials and cohort studies. British Medical Journal, 346, e7492. doi: 10.1136/bmj.e7492

Tuorila-Ollikainen, H., \& Mahlamaki-Kultanen, S. (1985). The relationship of attitudes and experiences of Finnish youths to their hedonic responses to sweetness in soft drinks. Appetite, 6(2), 115-124.

U.S. Department of Health and Human Services and U.S. Department of Agriculture. (2015). 20152020 Dietary Guidelines for Americans. Retrieved from http://health.gov/dietaryguidelines/2015/guidelines/.

Vaala, S. E., Bleakley, A., Hennessy, M., \& Jordan, A. B. (2016). Weight Stigmatization Moderates the Effects of Sugar-Sweetened Beverage-Related PSAs Among U.S. Parents. [Article in Press]. Media Psychology, 1-27. doi: 10.1080/15213269.2015.1121826

Wakefield, M. A., Loken, B., \& Hornik, R. C. (2010). Use of mass media campaigns to change health behaviour. Lancet, 376(9748), 1261-1271. doi: 10.1016/s0140-6736(10)60809-4

Wardle, J., Parmenter, K., Waller, J. . (2000). Nutrition knowledge and food intake. Appetite, 34, 269275.

Wilkinson, R., Marmot, M. (2003). Social determinants of health: The solid facts (2nd ed.). Copenhagen: World Health Organization.

Witte, K., \& Allen, M. (2000). A meta-analysis of fear appeals. Implications for effective public health campaigns. Health Education \& Behavior, 27(5), 591-615.

Wong, G., Greenhalgh, T., Westhorp, G., Buckingham, J., \& Pawson, R. (2013). RAMESES publication standards: meta-narrative reviews. BMC Med, 11, 20. doi: 10.1186/1741-7015-11-20

World Health Organization. (2015). Guideline: sugars intake for adults and children Geneva. Retrieved from http://who.int/nutrition/publications/guidelines/sugars intake/en.

Zoellner, J. M., Hedrick, V. E., You, W., Chen, Y., Davy, B. M., Porter, K. J.et al. (2016). Effects of a behavioral and health literacy intervention to reduce sugar-sweetened beverages: a randomized-controlled trial. International Journal of Behavioral Nutrition and Physical Activity, 13, 38. doi: 10.1186/s12966-016-0362-1

Zytnick, D., Park, S., Onufrak, SJ., Kingsley, BS., Sherry, B. (2015). Knowledge of Sugar Content of Sports Drinks Is Not Associated With Sports Drink Consumption. American Journal of Health Promotion, 30(2), 101-108 108p. doi: 10.4278/ajhp.130916-QUAN-479 
